\title{
Supralevator Abscess Complicated by Necrotic Fasciitis of Peritoneum, Genitalia, Anterior Abdominal Wall and Retroperitoneum
}

\author{
Elena Hadzhieva ${ }^{1,3^{*}}$, Dzhevdet Chakarov ${ }^{1}$, Evgenii Moshekov ${ }^{1}$, Dimitar Hadzhiev ${ }^{1}$, \\ Yordan Kalchev ${ }^{1}$, Kiril Atliev ${ }^{2}$, Boris Sakakushev ${ }^{1,3}$
}

Received: 20 April 2021 / Accepted: 05 May 2021 / Published online: 20 July 2021

This article is published with open access at https://journal.astes.org.al

(C) The author(s) 2021. \& Copyright (C) 2021, the Albanian Society for Trauma and Emergency Surgery

(c) The Albanian Journal of Trauma and Emergency Surgery is an Open Access Journal. All articles are distributed under the terms of the Creative Commons Attribution Non-Commercial License: http://creativecommons.org/licenses/by-nc/4.0/) which permits unrestricted non-commercial use, distribution, and reproduction in any medium provided the original work is properly cited.

\begin{abstract}
A supralevator anorectal abscess may lead to a rare clinical complication, such as perineal necrotizing fasciitis. A 57-year-old man was admitted on an emergency basis with evidence of a deep anorectal abscess of 5-day duration. The clinical presentation involved an unbounded purulent destructive inflammation spreading onto the adjacent areas, with the development of a septic condition. Following a short preparation, a radical surgical debridement of a subfascial purulent necrotic phlegmon of the pelvic space was performed. Since the lower part of the abdomen, retroperitoneum and scrotum were involved, 4 additional subsequent necrectomies were performed at 48 -hour intervals. The aggressive radical operative treatment and the combined intensive therapy were the main contributors to the favorable outcome of the disease.
\end{abstract}

Keywords: supralevator abscess, necrotizing fasciitis, Fournier's gangrene

\section{Introduction}

The supraelevator abscess is the most complex variant of deep anorectal abscesses, because its symptoms are not specific and are rarely manifested initially, which results in a delayed diagnosis and surgical treatment [1,2]. A comparatively rare complication of this abscess is the perineal necrotic fasciitis which occurs in people with immunosuppressive concomitant diseases. It is manifested as a progressive and generalized phlegmonous destructive inflammation of the soft tissues of the perianal, perineal, genital and gluteal regions, invasively involving even the

Original article, no submission or publication in advance or in parallel

* Corresponding author:

Elena Hadzhieva MD

$\bowtie$ eli_hadzhieva@yahoo.com

1 First Clinic of Surgery, University Hospital "St. George", Plovdiv, BULGARIA

2 Emergency Surgical Department2, University Hospital "St. George", Plovdiv, BULGARIA

3 Medical University of Plovdiv, BULGARIA lower part of the anterior abdominal wall. The disease was described in detail for the first time as genital gangrene in 1883 by J. Fournier [3]. Initially, the disease may have a different clinical origin, but most frequently it is the resultant complication of an anorectal inflammatory process; more rarely it occurs following a genital or dermatological disease [4]. A characteristic feature resulting from the spread of this process is the progressive deterioration of the patient's general condition, with the symptoms of sepsis, increasing proportionally to the newly involved areas [5].

\section{Case presentation}

We report a case of clinical interest, manifested as a supralevator abscess complicated by progressive necrotizing fasciitis of the peritoneum, genitalia, anterior abdominal wall and retroperitoneal space. The patient M.M., aged 57, with case history № 66509/2997 of 2020 was admitted on an emergency basis to St. George University Hospital of Medical University - Plovdiv, First Clinic of Surgery on Nov. 16, 2020 with subjective symptoms of a deep anorectal abscess. For 5 days he was suffering from increasing pain in the perineum and the anal area, accompanied by weakness, discomfort, general feebleness and insomnia. His 
temperature gradually rose to $38^{\circ} \mathrm{C}$, and he had shivers. He complained of dysuria and received treatment for "inflamed hemorrhoids". On the 4-th day the pains became intensive and constant in nature, the swelling spread, involving the scrotum and the gluteal region. Oedema gradually occurred in the lower part of the anterior abdominal wall. He never suffered from inflammatory diseases in the regions involved-

The clinical examination on admission revealed a severely affected general condition, weakness, febrility of $38.5^{\circ} \mathrm{C}$, tachycardia/110 beats/min/, hypotension/BP 85/60/, suggesting septic condition. Insulin-dependent diabetes mellitus was diagnosed on admission.

The local status observed tender and reddened infiltrate in the perianal, scrotal and gluteal areas with an extensive phlegmonous inflammation not demarcated from the surrounding tissues, at some sites with inflammatory and ischemic alterations of the overlying skin. There was diffusely manifested edema in the areas involved, with soft texture and locally increased temperature. The anorectal digital examination revealed a deep tender infiltrate with blurred boundaries and solid texture.

The laboratory blood tests showed leukocytosis (WBC)-20.98 x 10^9/1, elevated blood sugar - $25.3 \mathrm{mmol} / \mathrm{l}$, total protein - $54.0 \mathrm{mmol} / \mathrm{l}$, total bilirubin - $28.5 \mathrm{mmol} / \mathrm{l}$, amylase - 152.0, elevated C-reactive protein (CRP) - 377.0, urine - glucose $3(+)$ pos., ketone bodies $2(+)$ pos. The remaining biochemical investigations and the coagulation tests were within reference values.

Abdominal radiograph revealed no gas collection or hydroaeric shadows.

Following a short preparation the patient underwent emergency surgery under general anesthesia. A deep incision was made in the right supralevator space, which exposed a large $250-\mathrm{ml}$ purulent collection with a putrid smell. A specimen was sent for a microbiological investigation, after which a digital revision of the cavity was performed, including removal of the adhesions and septa. Several incisions were performed in the lower anterior abdominal wall, the scrotum and the gluteal region. Incisions into the perineal space followed, where marked necrotic areas were found. Non-abundant purulent secretion was observed with putrid smell, from a pelvic subfascial purulent necrotic phlegmon, not clearly demarcated from the adjacent tissues. Fasciotomy and necrectomy was performed, followed by drainage.

A day-to-day postoperative control was required, with the bandage changed twice daily. Surgical debridement for newly involved purulent necrotic areas was performed every 48 hours under general anesthesia. A total of 4 planned revisions were done, with subsequent re-incisions, necrectomies and drainage. The 2-nd surgical debridement found involvement of the retroperitoneal space, which resulted in two incisions, necrectomy and drainage (Fig.1).

The 3-rd postoperative revision required bilateral orchiectomy, because of the progressive purulent phlegmonous inflammation, disrupted vascular circulation and necrosis of the testicles.

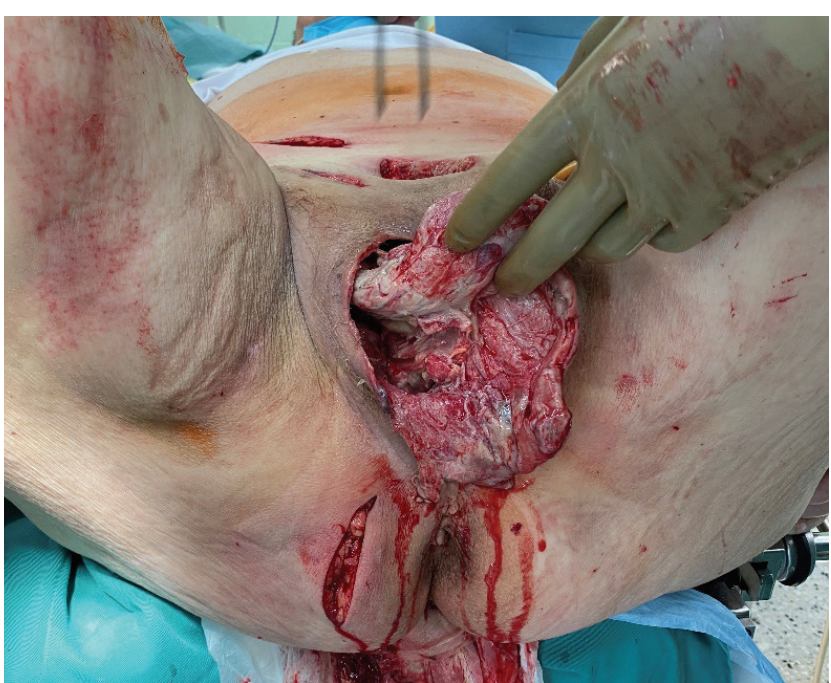

Figure 1. A Fournier's gangrene after debridment.

Complex and intensive resuscitation and antiinflammatory therapies were applied simultaneously with the surgical treatment. Initial empirical antibacterial treatment was started, with broad-spectrum antibiotics, including metronidazole, subsequently modified according to the microbiological findings. The result from the microbiological investigation № 10648/2020 showed Escherichia coli.

The final diagnosis was: Right supralevator abscess. Necrotizing fasciitis of the perineum, gluteus, scrotum, retroperitoneum space and abdominal wall. Fournier's Gangrene. Concomitant diseases: Diabetes. Left side kidney calculus.

The postoperative period had a comparatively smooth course. Two follow-up examinations were performed after discharge from hospital, with insignificant complaints registered. The 4-th month follow-up after hospitalization disclosed no complaints, the patient was feeling well.

The good outcome resulted from the maximally radical primary surgery applied and the subsequent revisions with urgent necrectomies. The main problem of this complicated supralevator abscess was the achievement of a timely optimal control over the phlegmonous destructive process [6]. The presence of the newly found diabetes was related to the patient's lowered immunity, which led to rapid progression of the inflammatory process. Whenever possible, magnetic resonance imaging is an important method in determining the localization of the primary inflammatory focus, as well as the choice of an efficient approach to surgical drainage [7]. According to A. Gupta et al. [8], the disease is manifested as gangrene of the skin and the underlying subcutaneous tissue resulting from thrombotic vasculitis. They point out that the underlying muscles are preserved, uninvolved by the necrotic process, having no evidence of purulent myositis. Various indices are used for the prognosis and evaluation of disease severity - Fournier's Gangrene Severity Index (FGSI) - with a maximum of 15 pts and 
Uludag Fournier's Gangrene Severity Index (UFGSI) $[9,10]$. Some authors apply adjuvant hyperbaric oxygen therapy or vacuum assisted therapy [11]. The aggressive surgical treatment includes a step approach, where timely identification and elimination of the source of infection is of crucial importance for the outcome [12]. Of similar significance were the timely, repeated revisions involving extensive and radical surgical debridement with wide excisions to expose the necrotic areas until healthy tissue was reached [13].

\section{Conclusion:}

This case of supralevator abscess, complicated by necrotizing fasciitis demonstrates scarce, non-specific initial local symptoms and rapid diffuse progression of the destructive process without demarcation. Aggressive repeated debridement is the cornerstone lifesaving procedure of choice. This include wide necrectomy of the purulent destructive areas and timely revisions of the newly formed purulent cavities, leading to a favourable outcome.

COI Statement: This paper has not been submitted in parallel. It has not been presented fully or partially at a meeting or podium or congress. It has not been published nor submitted for consideration beforehand.

All authors declare that there is no conflict of interest. This research received no specific grant from any funding agency in the public, commercial, or nonprofit sectors. There are no relevant or minor financial relationships from authors, their relatives or next of kin with external companies.

Disclosure: The authors declared no conflict of interest. No funding was received for this study.

\section{References:}

1. Aparício D., Leichsenring $\mathrm{C}=$, Sobrinho $\mathrm{C}=$, Pignatelli $\mathrm{N}$, Geraldes V, Nunes V. Supralevator abscess: New treatment for an uncommon aetiology: Case report. Int J Surg Case Rep. 2019; 59: 128-131.
2. Oikonomou C, Alepas P, Gavriil S, Kalliouris D, Manesis K, Bouboulis P, Filippou D, Skandalakis P. A Rare Case of Posterior Horseshoe Abscess Extending to Anterolateral Extraperitoneal Compartment: Anatomical and Technical Considerations. Ann Coloproctol. 2019 May 31;35(4):216220.

3. Kuzaka B, Wróblewska MM, Borkowski T, Kawecki D, Kuzaka P, Młynarczyk G, Radziszewski P. Fournier's Gangrene: Clinical Presentation of 13 Cases. Med Sci Monit. 2018 Jan 28; 24: 548-555.

4. Czymek R, Hildebrand P, Kleemann M, Roblick U, Hoffmann M, Jungbluth T, Bürk C, Bruch HP, Kujath P. New insights into the epidemiology and etiology of Fournier's gangrene: a review of 33 patients. Infection. 2009 Aug;37(4):306-12.

5. Gadler T, Huey S, Hunt K. Recognizing Fournier's Gangrene in the Emergency Department. Adv Emerg Nurs J. 2019 Jan/ Mar;41(1):33-38.

6. Sanyal S, Khan F, Ramachandra P. Successful management of a recurrent supralevator abscess: a case report. Case Rep Surg. 2012; 871639 .

7. Garcia-Granero A, Granero-Castro P, Frasson M, FlorLorente B, Carreño O, Espí A, Puchades I, Garcia-Granero E. Management of cryptoglandular supralevator abscesses in the magnetic resonance imaging era: a case series. Int J Colorectal Dis. 2014 Dec;29(12):1557-64.

8. Gupta A., Dalela D., Sankhwar S., Goel M., Kumar S., Goel A. Bilateral testicular gangrene: does it occur in Fournier's gangrene? Int. Urol. Nephrol., 2007, 39, 3, 913-915.

9. Sparenborg JD, Brems JA, Wood AM, Hwang JJ, Venkatesan $\mathrm{K}$. Fournier's gangrene: a modern analysis of predictors of outcomes. Transl Androl Urol. 2019 Aug;8(4):374-378.

10. Y1lmazlar T., Işık O., Öztürk E., Özer A., Gülcü B. Fournier‘s gangrene: review of 120 patients and predictors of mortality, Ulus Travma Acil Cerrahi Derg., 2014 Sep;20(5):333-7.

11. Singh A, Ahmed K, Aydin A, Khan MS, Dasgupta P. Fournier's gangrene. A clinical review. Arch Ital Urol Androl. 2016 Oct 5;88(3):157-164.

12. Pehlivanli F, Aydin O, Karaca G, Aydin G, Erden Daphan Ç. An Extremely Rare Complication of Widespread Retroperitoneal Abscess Originating from Anorectal Horseshoe Abscess. Bull Emerg Trauma. 2019 Jan;7(1):72-75.

13. Hagedorn JC, Wessells H. A contemporary update on Fournier's gangrene. Nat Rev Urol. 2017 Apr;14(4):205-214. 